\title{
Rapid Assessment of Earthquake Source Characteristics
}

\author{
by Semechah K. Y. Lui, Don Helmberger, Junjie Yu, and Shengji Wei
}

\begin{abstract}
Recent studies emphasize the rapid assessment of earthquake source properties, such as moment magnitude, to help alleviate the impact of earthquakes. Depending on local crustal structure, earthquakes occurring at different depths can differ greatly in high-frequency motions, which emphasizes the importance in constraining focal depth for the predictions of strong motions. For large earthquakes, assessing rupture directivity is also essential in estimating ground-motion effects throughout the source region. In this article, we perform an in-depth study on a group of recent earthquakes near the intersection of the San Jacinto and San Andreas fault systems in southern California. We develop a systematic method to accurately estimate moment magnitude and focal mechanism within 3-6 s after the first $P$ arrival. Focal depth can also be constrained within $\sim 10$ s upon the arrival of $S$ waves. To determine the direction of fault rupture, we implement a forward-modeling method, which takes smaller earthquake recordings as empirical Green's functions to simulate the rupture direction of the beginning motion generated by larger events. With a small event nearby, we resolve the rupture characteristic of the $2014 M_{\mathrm{w}} 4.4$ event using information at stations within $35 \mathrm{~km}$ from the epicenters and successfully predict the ground-motion response at stations at farther distances, where directivity effect is significant. Rupture direction of simulated earthquakes with larger magnitudes can also be accurately resolved using the method proposed, opening a possibility to predict ground motions ahead of time, in particular for hazardous regions.
\end{abstract}

Online Material: Figures of inversion results, waveform fits, directivity, and ground-motion prediction analysis; and table of crustal model.

\section{Introduction}

The increased seismic-station coverage associated with early warning and real-time seismology provides an opportunity to study strong-motion predictability. Early warning implies a prediction, that is, just what level of shaking is expected. In particular, many large earthquakes are preceded by foreshocks, and nearly all have aftershocks, some of which are quite damaging. Predicting the level of shaking for these smaller events with testable accuracy is hence fundamental in establishing creditability. In short, although treating earthquakes as centroid moment tensors proves effective at longer periods $(>5 \mathrm{~s})$, shorter periods $(0.5-10 \mathrm{~Hz})$ must be addressed in the strong-motion band, in which uncertainties in focal depth and rupture directivity become essential issues.

\section{Small Earthquakes as Useful Resources}

Over the past decade, several earthquakes with $M_{\mathrm{w}}>5$ occurred in the southern California region, showing intriguing observations. Two of them were the $M_{\mathrm{w}} 5.4$ Chino Hills event in 2008 (Fig. 1) and the $M_{\mathrm{w}} 5.4$ Brawley event in
2012 (Fig. 1, inset). These moderate events have allowed indepth studies, including their source and rupture characteristics (Hauksson et al., 2008; Geng et al., 2013, Wei et al., 2013). Interesting findings include the Brawley event being an indirect triggered source due to nearby fluid injection wells (Wei et al., 2015). With the earthquake epicenters located near a populated area as well as the proximity of the Brawley earthquake to one of the geothermal energy production sites, there is high incentive to convey earthquake information as quickly and accurately as possible. Therefore, at the initial stage, we explored different methods to efficiently resolve the source characteristics, in particular the moment magnitude and focal mechanism. Instead of using the entire network to resolve focal mechanisms, we managed to recover reasonable results using the $P$ arrivals at nearby stations. The first $P$ wave of the Brawley event reached the closest station WLA within $3 \mathrm{~s}$. With only a single station, focal mechanism could be recovered within $10 \mathrm{~s}$ and moment magnitude within $20 \mathrm{~s}$. With both stations WLA and SNR, similar results can be recovered (Fig. 2). For the Chino Hills event, with waveform 


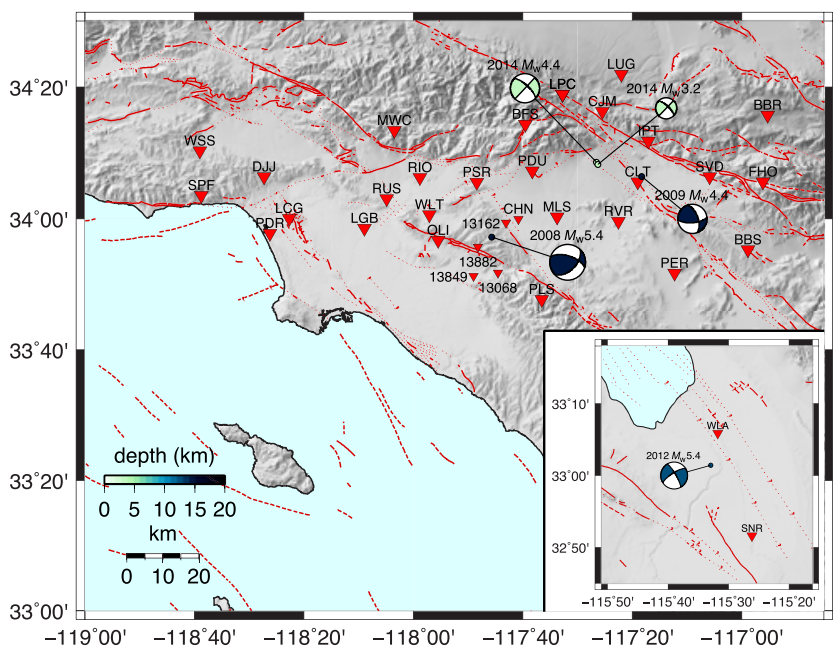

Figure 1. Overview of the study region of this project near the city of Fontana located near the San Andreas fault. The Californian fault system is delineated by dashed lines. Inverted triangles are selected CI network stations used for this study. The epicenter location and focal mechanism of several prominent earthquakes in the study area are shown, with the shade of the focal mechanism symbols indicating the focal depth. (Inset) Local map showing the 2012 $M_{\mathrm{w}} 5.4$ Brawley event. Stations WLA and SNR are used in preliminary studies on real-time source characterization. The color version of this figure is available only in the electronic edition.

at four stations, moment magnitude and focal mechanism converge to the full-array inversion results within $12 \mathrm{~s}$ after the first arrival. (The results for the Chino Hills event are displayed in (E) Fig. S1, available in the electronic supplement to this article.) These preliminary results motivate a systematic analysis to rapidly assess earthquake characteristics for events at all sizes, including important source parameters, and to distill crucial information for the necessary steps to implement in hazard mitigation.

Data from Earthquakes near Fontana, California, as a Test Case

More recently, a number of earthquakes that occurred in Fontana, California, provide key data to address these issues. This region is located near the intersection of the San Andreas and San Jacinto faults and has been seismically active throughout the years (Fig. 1), hosting earthquakes with a wide range of size and focal depth. The possible onset of a large rupture nucleation at the intersection of the two major faults may extend on either fault line and in either direction. At present, one of the major pressing concerns is the potential damaging response of the Los Angeles basin to any earthquakes occurring outside it and in particular at this intersection (Jones et al., 2008). Therefore, our investigation extends to retrieving rupture properties of the earthquakes, including the rupture plane and the direction of rupture, which is crucial information in estimating the effects of the source to neighboring areas at all azimuths. We also aim to investigate the source and path effects of the corridor along the San Bernardino Valley and the Los Angeles basin.

Two $M_{\mathrm{w}} 4.4$ earthquakes near Fontana, which occurred in 2009 and 2014, respectively, are compared in our study. They have similar epicenter locations, moment magnitude $\left(M_{\mathrm{w}} 4.4\right)$, and strike-slip focal mechanisms. However, the 2009 event occurred over $10 \mathrm{~km}$ deeper than the 2014 event and produced distinctly different motions (Fig. 3). Although broadband waveforms show similar amplitude range, the deep event has much higher energy content when waveforms are filtered to a $3-10 \mathrm{~Hz}$ frequency range at station RUS, which is located at the edge of the Los Angeles basin. In this frequency range, a wide range of buildings will be significantly affected. This phenomenon is found consistent at nine other stations spanning $\sim 80 \mathrm{~km}$ from east to west along this narrow corridor (see (E) Fig. S2).

In short, focal depth plays a more significant role in contributing to the extent of shaking in the basin area than expected. Currently the earthquake early warning (EEW) algorithm focuses on retrieving the correct epicenter location and moment magnitude with 3 s of waveforms (Kanamori, 2005; Wu and Kanamori, 2005, 2008). These intriguing observations emphasize the importance of constraining focal depth.

For all the reasons above, we select earthquakes near Fontana as test cases to perform a comprehensive and systematic analysis in characterizing earthquake source and rupture properties, including moment magnitude, focal mechanism and depth, and rupture direction and dimension, using close-by stations. Besides aiming to quickly extract information from real-time data, we also investigate how accurately we can further predict ground motion at farther distances, based on these results.

\section{Methodology}

In this study, the cut-and-paste (CAP) method is the primary tool to model waveforms recorded at selected stations (Zhao and Helmberger, 1994; Zhu and Helmberger, 1996). This approach compares the $P n l$ and surface-wave segments separately with waveforms from a synthetic source. Because differential time shifts are allowed among the different segments of the complete wavefield, this approach results in accurate source estimates even with synthetic Green's functions generated from imperfect 1D velocity models or poorly located events. Here, we compute the Green's functions using a frequency-wavenumber integration method (Zhu and Rivera, 2002), and the CAP approach determines via grid search the optimal moment magnitude, conjugate fault planes, and focal depth. Typically, depth is constrained from the surfacewave to body-wave amplitude ratio as well as from depth phases in the $P n l$ wavetrains.

To resolve rupture characteristics of these events, we follow the approach developed by Tan and Helmberger (2010), a modeling technique that utilizes both duration and amplitude information to estimate rupture directivity. In their analysis, a small nearby event is selected as the empirical Green's 



Figure 2. Preliminary test on the 2012 Brawley event. (a) Map view of event and station location with focal mechanism of the $M_{\mathrm{w}} 5.4$ earthquake. The solid, dashed, and dotted circles indicate the different arrival times of $P$ and $S$ waves, assuming the path-calibrated velocity model (Wei et al., 2013). (b) Inversion results at station WLA with 4, 8, and $20 \mathrm{~s}$ of waveform are displayed. The two rows of numbers below the seismograms represent (top) time shift (in seconds) of the synthetic waveform relative to the data and (bottom) cross-correlation value. The labels to the left of the seismogram are (top) epicentral distance, (middle) station ID, and (bottom) azimuth. (c) The waveform inversion results reported as a function of waveform availability. The two nearest TriNet stations (WLA and SNR) were used separately and jointly. The number above the focal mechanism symbol is the estimated moment magnitude at each stage. The color version of this figure is available only in the electronic edition.
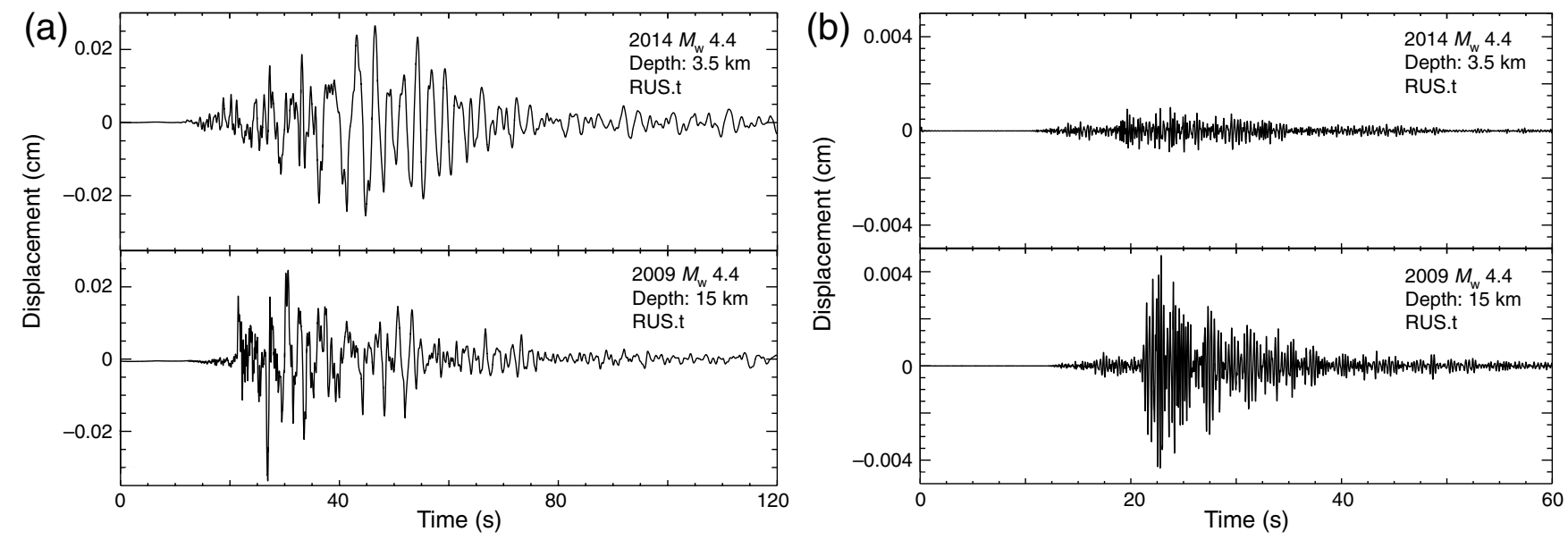

Figure 3. Significant difference in energy content for earthquakes at different focal depths. The tangential responses at station RUS near downtown Los Angeles, at a distance of (1) $60 \mathrm{~km}$ for shallow event and (2) $72 \mathrm{~km}$ for the deep event. (a) Broadband waveform indicates the strong late phase (8 s back) for the deep event, which is likely $s S m S$ (Helmberger et al., 1993). (b) The high-frequency (3-10 Hz) energy radiation is also much stronger for the deep event by a factor of 5 .

functions (EGFs) event. A grid search is conducted to solve for a common rise time $\tau_{r}$ and rupture duration time $\tau_{c}$ at individual stations that minimize the total waveform misfit error

$$
e=\sum_{i=1}^{N}\left[d_{i}(t)-\Delta M_{0} g_{i}(t) *\left(\tau_{r} * \tau_{c i}\right)\right]
$$

in which $d_{i}(t)$ and $g_{i}(t)$ represent records from the target event and the EGF event, and $\Delta M_{0}$ is a scaling factor to account for the two events being different in size (and radiation pattern, if applicable). $\tau_{r} * \tau_{c}$ is the relative source time function (STF) of the target event with respect to the EGF event. The summation is over all the selected stations. In a simple scenario of unilateral horizontal rupture on a vertical fault, the variation of $\tau_{c}$ can be modeled with

$$
\tau_{c}=\frac{\mathrm{fl}}{V_{r}}-\frac{\mathrm{fl}}{V_{P, S}} \cos (\varphi-\phi),
$$

in which fault length (fl) and rupture speed $\left(V_{r}\right)$ can be easily estimated. $\varphi$ and $\phi$ are the rupture propagation direction and the station azimuth, respectively. In the $2003 \mathrm{Big}$ Bear sequences, the a priori Haskell source model facilitates estimation of rupture parameters such as fault length (fl) and rupture speed $\left(V_{r}\right)$. This method has been successfully implemented in another study by Luo et al. (2010) on the widely felt $M_{\mathrm{w}} 4.6$ 


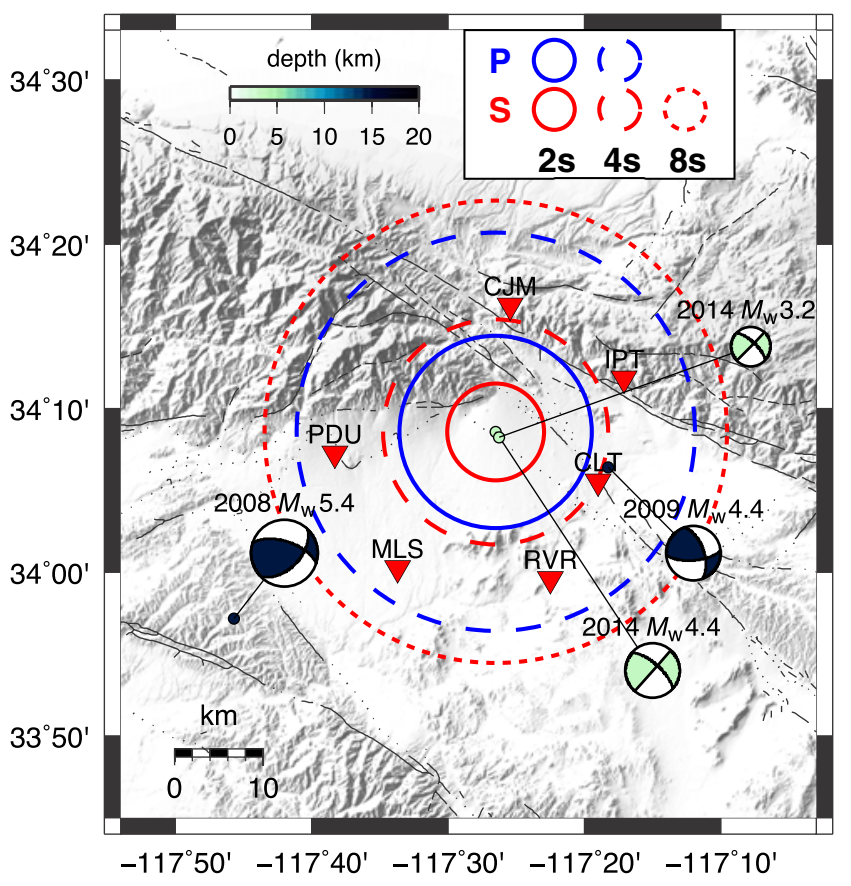

Figure 4. Stations near the epicenters are selected for rapid assessment of source parameters. Circles (solid/dashed/dotted) represent the arrival of $P$ and $S$ waves at 2, 4, and $8 \mathrm{~s}$ after the origin time. Within $4 \mathrm{~s}, P$ wave has reached the six closest stations. The color version of this figure is available only in the electronic edition.

earthquake in Inglewood, California. They used aftershocks as EGFs and retrieved rupture directivity of the mainshock directing to the southeast, which is consistent with the orientation of the Newport-Inglewood fault (see (E) Fig. S3). Another approach to study rupture characteristics is to use EGF based on the generalized ray theory (Helmberger, 1983). The target event is simulated by a summation of EGF events assumed as point sources, with each of them varied by a small time difference, depending on their shift in horizontal and vertical direction from the original point of nucleation. (For details, see the Appendix.) Previously, we used this approach to simulate the rupture properties of an intraslab event in the Tohoku-Oki region with an aftershock that occurred at a similar location (Lui et al., 2015).

\section{Analysis and Results}

Three Fontana events are selected for our analysis. First, the two Fontana earthquakes mentioned in the Introduction are subjected to detailed comparison as we determine their source characteristics using the CAP method. Their epicenters are $\sim 13 \mathrm{~km}$ apart, with the deep event slightly to the east. We also selected the biggest aftershock of the shallow event in 2014, with $M_{\mathrm{w}} 3.2$ and at a similar location, to be the EGF event for studying the directivity of the shallow $M_{\mathrm{w}} 4.4$ event. The two events need not have the same mechanisms, but their source parameters must be determined by other means, that is, CAP, from Green's functions. Mechanisms can be determined down to $M_{\mathrm{w}} 2$ using the method applied in Tan and Helmberger (2007). Such a library can be generated for many locations in southern California given the level of seismicity.

\section{Real-Time Assessment of Source Parameters}

For the purpose of comparison, we first model the waveforms of the two events with a larger group of stations in the Southern California Seismic Network (SCSN), within an epicentral distance of $500 \mathrm{~km}$. The inversion is done up to $0.2 \mathrm{~Hz}$ for $P n l$ waves and up to $0.1 \mathrm{~Hz}$ for surface waves. With CAP inversion, the respective strike, dip, and rake values are $44^{\circ}, 88^{\circ}$, and $31^{\circ}$ for the shallow event, and $81^{\circ}, 70^{\circ}$, and $82^{\circ}$ for the deep event. Their focal depths are 3.5 and $15 \mathrm{~km}$ respectively (see (E) Fig. S4). These parameters will be called network mechanism and network depth. The results are similar to what is reported in the SCSN catalog: the respective strike, dip, rake, and focal depth values are $33^{\circ}, 87^{\circ}$, $26^{\circ}$, and $2.9 \mathrm{~km}$ for the shallow event, and $83^{\circ}, 73^{\circ}, 22^{\circ}$, and $14.2 \mathrm{~km}$ for the deep event.

With accurately determined source characteristics, the next step is to investigate how quickly and accurately these results can be obtained within a short time after an earthquake occurs, on the order of seconds after the first $P$ arrival. For the 2014 shallow event, we selected a group of six nearby stations, which are within an epicentral distance of $20 \mathrm{~km}$ and form a close ring of seismic recording for the shallow event, providing good azimuthal coverage (Fig. 4). The $P$ wave reached these stations within $4 \mathrm{~s}$ after the origin time, whereas the $S$ wave arrived at the stations within $8 \mathrm{~s}$. By applying CAP on waveforms recorded at only these six stations, source parameters evolve as more and more seismic data are available for inversion. Eventually all parameters match with the network mechanism. With only $3 \mathrm{~s}$ of incoming waveform, strike and dip inversions are already within $10^{\circ}$ from the network mechanism (Fig. 5a). The waveform cross correlations are also above $90 \%$ for most of the vertical and radial components at stations. Furthermore, moment magnitude differs by less than 0.1 from the network inversion estimate. Because focal depth can only be accurately determined after the arrival of $S$ waves, we only assume an average hypocenter depth in the area $(\sim 7 \mathrm{~km})$ for the 3 and $6 \mathrm{~s}$ inversion. With $10 \mathrm{~s}$ of waveform, including the incoming $S$ phase, we then also perform a grid search on focal depth. For the deep event in 2009, a slightly different group of stations are selected, due to the difference in event location. Station CLT is clipped in this case, given its $<2 \mathrm{~km}$ distance from the source. Nonetheless, a similar level of accuracy is obtained from the inversion (Fig. 5b). The 2014 and 2009 earthquakes are constrained at a depth of 3.5 and $14 \mathrm{~km}$, respectively, which are almost identical with network depth. As a check, we reran the 3 and $6 \mathrm{~s}$ inversion with the updated focal depths, and similar results are obtained. This indicates that preliminary seismic moment and focal mechanism estimates are not heavily dependent on focal depth as demonstrated in Figure 5. 
(a)

Focal depth fixed

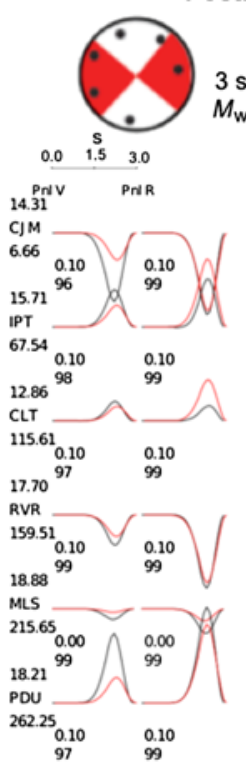

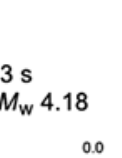

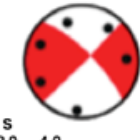

$6 \mathrm{~s}$

$M_{\mathrm{w}} 4.36$

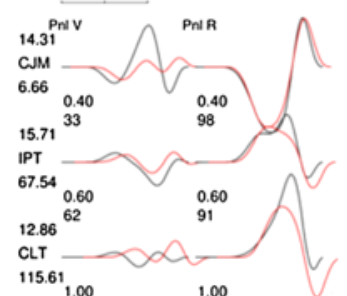

${ }^{115.61}{ }_{1.00}$
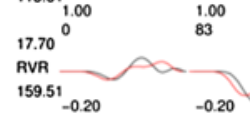

$18.88^{-0.20}$

18.88
MLS
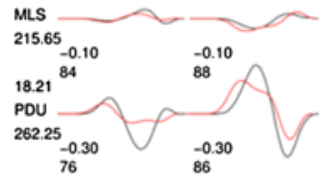

86
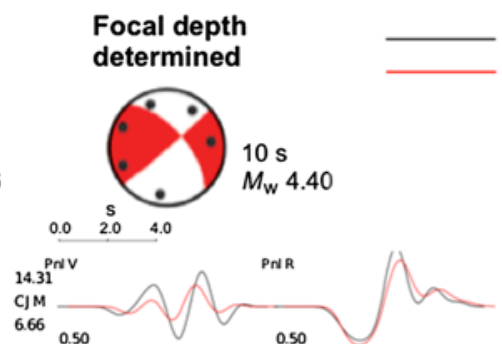

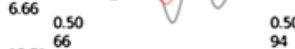

15.71
IPT

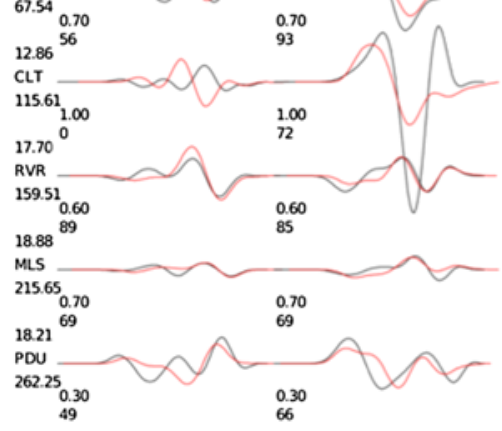

Focal depth

determined

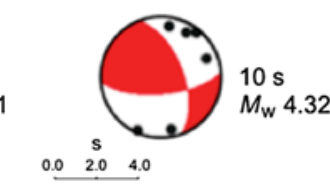

1.99

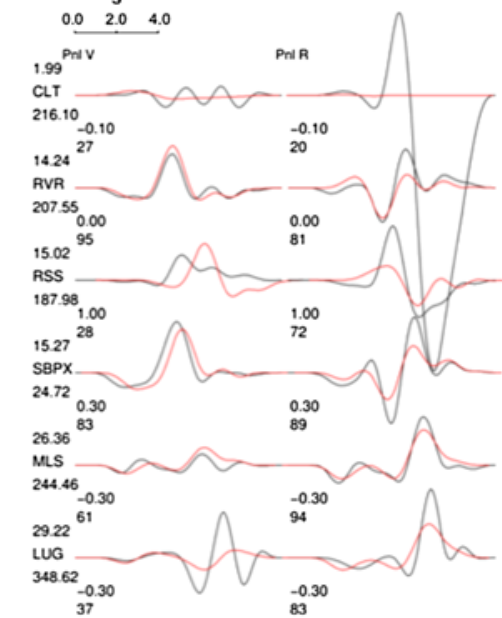

Data

Synthetics

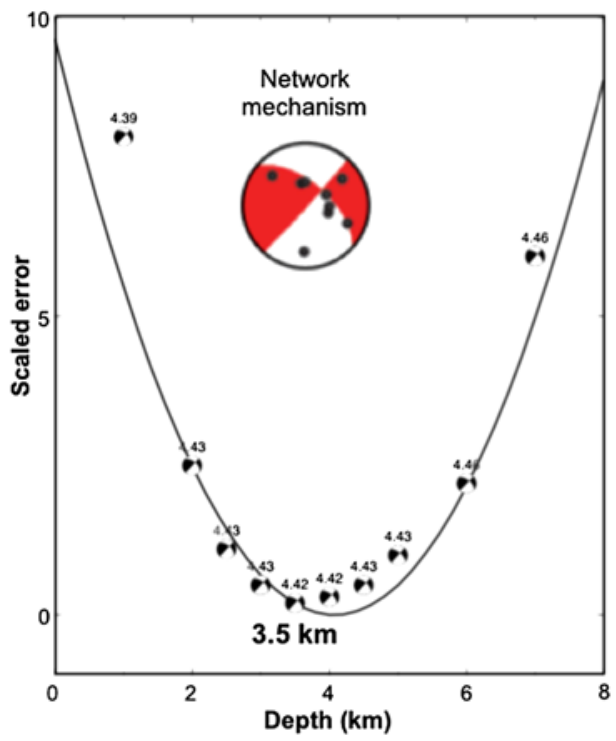

(b)

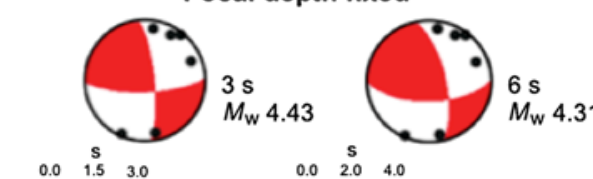

Pnl PnI R

CLT

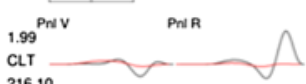

$\begin{array}{ll}-0.10 & -0.10 \\ 79 & 97\end{array}$

14.24

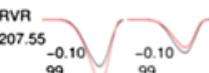

$\begin{array}{ll}-0.10 & -0.10 \\ 99 & -10\end{array}$

15.02

187.98

$15.27^{-0.20} \quad 0^{-0.20}$

$58 \mathrm{PX}$

24.72
26.36

26.36
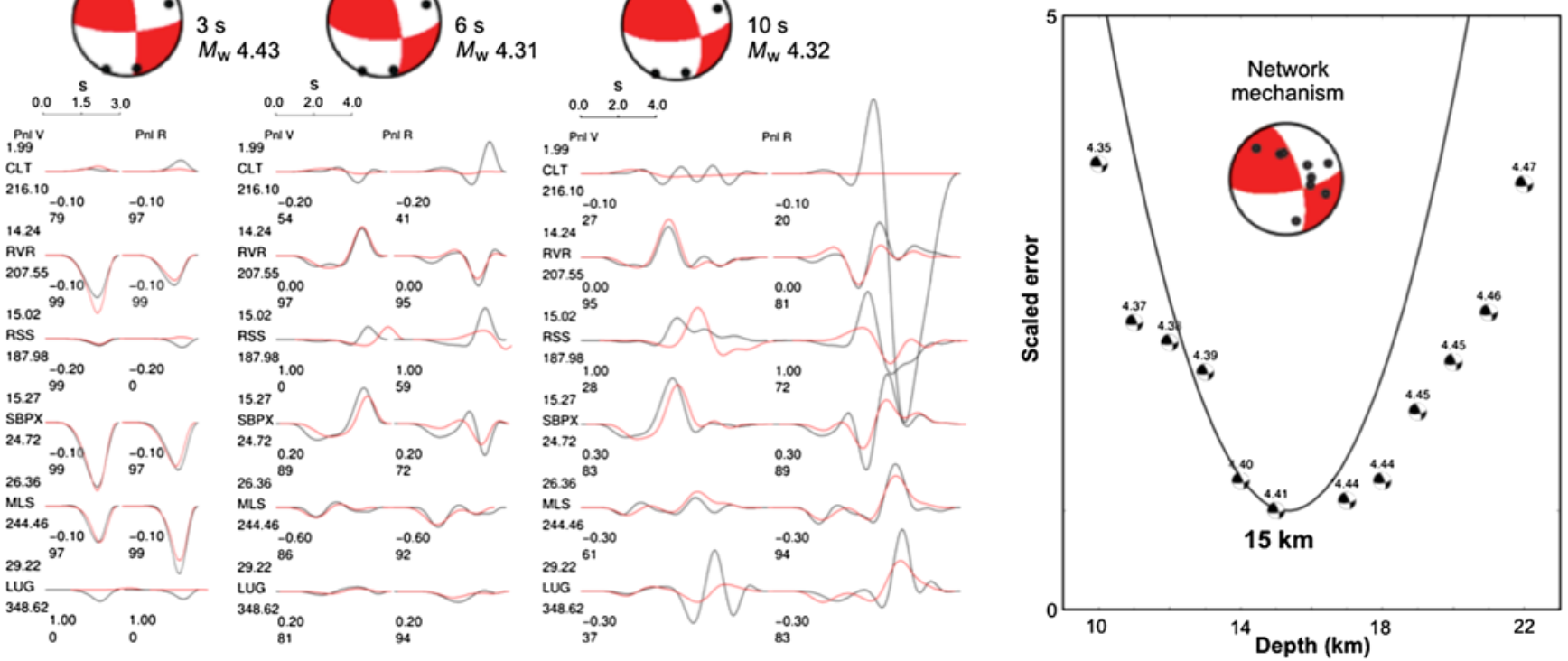

Figure 5. Cut-and-paste method allows accurate and fast characterization of moment magnitude, focal mechanism, and depth. (a) Inversion with 3, 6, and $10 \mathrm{~s}$ of waveforms for the shallow 2014 event with $M_{\mathrm{w}} 4.4$. The figure to the right displays scaled errors from grid search on focal depth. Focal depth can be determined once the $S$ wave arrives (within $10 \mathrm{~s}$ in this case). Before the $S$-wave arrival, a focal depth $(h=7 \mathrm{~km})$ is assumed when conducting inversions. The labeling of the seismograms follows that of Figure $2 \mathrm{~b}$. (b) Analogous inversion results for the deep $2009 M_{\mathrm{w}} 4.4$ event. The color version of this figure is available only in the electronic edition.

\section{Assessing Rupture Properties}

Although source mechanism and focal depth can be well determined within $10 \mathrm{~s}$ after the first arrival, for much larger earthquakes, it is also important to obtain information regarding the rupture direction and dimension with growing moment magnitude. In the same area near Fontana, an $M_{\mathrm{w}} 3.2$ aftershock occurred at almost the exact same location and similar depth as the shallow $M_{\mathrm{w}} 4.4$ event. The two events also have similar waveforms (see (E) Fig. S5) and share very similar focal mechanism according to the SCSN catalog. Because directivity effect lessens with decreasing magnitude, the $M_{\mathrm{w}} 3.2$ event is assumed to act like a point source compared to the target event. We compare the amplitude ratio of the first $2.5 \mathrm{~s}$ of vertical and radial $P$ waves for the $M_{\mathrm{w}} 4.4$ and 3.2 events at stations at all azimuths. Our results indicate that the ratio is much higher at stations to the northwest. This 


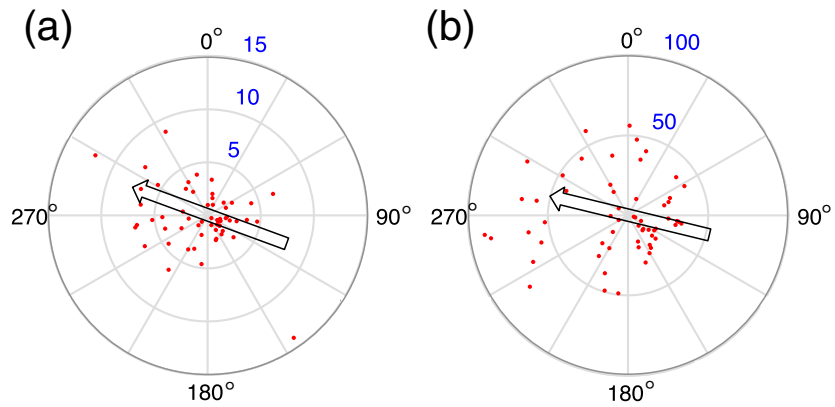

Figure 6. Directivity observed from difference in amplitude ratio of waveform across all azimuths. Using a smaller event near the mainshock, we compare the (a) vertical and (b) radial component amplitude ratio of the first $2.5 \mathrm{~s}$ of $P$ waves between the big and small events, as a function of azimuth. In the radial plot, each dot represents one station. Waveforms are filtered to $0.5-2 \mathrm{~Hz}$. The scale on the concentric circles is the amplitude ratio. The mainshock carries much higher energy to stations to the west and northwest, providing an early indication of rupture directivity. The color version of this figure is available only in the electronic edition.

preliminarily suggests that the $M_{\mathrm{w}} 4.4$ earthquake ruptured toward that direction (Fig. 6).

With this hypothesis, we then follow the forward-modeling approach in Tan and Helmberger (2010) and model the directivity of the $M_{\mathrm{w}} 4.4$ event using the $M_{\mathrm{w}} 3.2$ earthquake as the EGF event. EGF synthetics are generated by convolving the first $3 \mathrm{~s}$ of $P$ wave with a range of STFs, which have rupture duration $\tau_{c}$ ranging from 0.1 to $0.5 \mathrm{~s}$ and a best-fitting rise time $\tau_{r}$ at $0.1 \mathrm{~s} . \tau_{r}$ is insensitive in this study and is fixed at $0.1 \mathrm{~s}$ in real-time analysis. $P$ waves used for the forward calculation are filtered to $0.5-4 \mathrm{~Hz}$. $\Delta M_{0}$ is 63 in this case, accounting for the moment ratio between the two events. Results indicate a distinct variation of best-fitting STF across azimuth (Fig. 7). Station CLT, which is to the southeast of the epicenter at an azimuth of $114.0^{\circ}$, fits best with rupture duration $\left(\tau_{c}\right)$ of $0.45 \mathrm{~s}$. On the other hand, station LPC is located in the opposite direction with an azimuth of $333^{\circ}$, and $\tau_{c}=0.15 \mathrm{~s}$ fits best. For stations in other azimuths, $\tau_{c}$ is between 0.25 and $0.3 \mathrm{~s}$. The analysis validates the hypothesis that the $M_{\mathrm{w}} 4.4$ earthquake ruptured toward the northwest. This result is further validated when we include in the analysis the first-arriving $P$ waves at a group of 22 triggered stations (see (E) Fig. S6). The values of $\tau_{c}$ have a smooth variation with the maximum and minimum value corresponding to azimuths $120^{\circ}$ and $305^{\circ}$ (Fig. 8). The sensitivity of this analysis to frequency range is low, because we obtain similar results using waveforms filtered up to $2.5,4$, and $10 \mathrm{~Hz}$ (Fig. 8). A rupture direction of $\mathrm{az}=305^{\circ}$ is very similar to the strike value of one of the conjugate planes for the shallow event (strike $=313^{\circ}$ ). Based on results from the $P$-wave analysis and the assumed 1D velocity model, the estimated rupture length and rupture speed are $0.8 \mathrm{~km}$ and $2.9 \mathrm{~km} / \mathrm{s}$, respectively, according to equation (2).

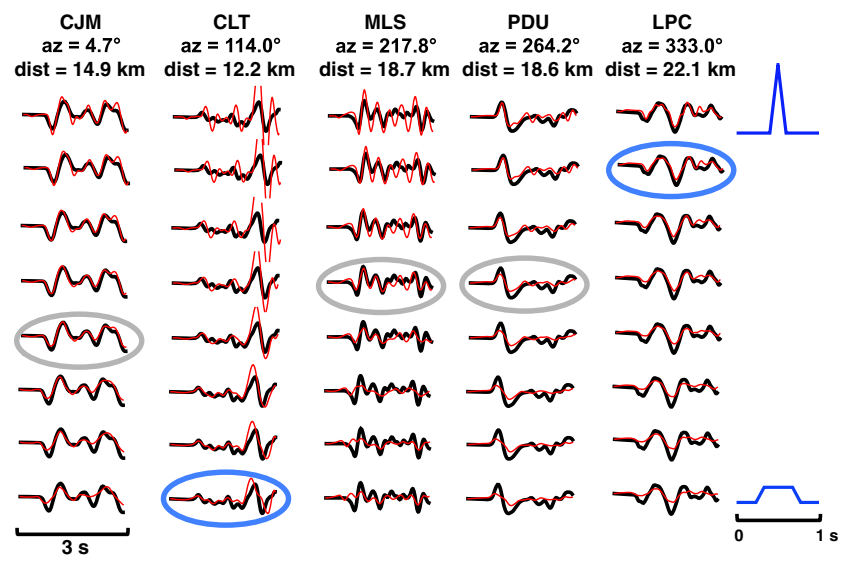

Figure 7. Predicting rupture directivity using incoming $P$ wave. Each column represents comparison of mainshock data at a station (radial component) with a range of empirical Green's functions (EGFs), which is the convolution of aftershock data with a specific source time function (STF). The best-fitting pairs are circled. Note that the variation across azimuth in the fit between data (thick lines) and EGFs (thin lines). The extreme cases at stations CLT and LPC suggest a rupture directing to the northwest. Refer to (E) Figure S6 (available in the electronic supplement to this article) for the results of all the remaining stations. The color version of this figure is available only in the electronic edition.

\section{Discussion}

The methodology proposed here allows a quick characterization of seismic moment, focal mechanism and depth, and rupture properties with the first $P$ and $S$ arrivals at stations within $35 \mathrm{~km}$ from the epicenter, which is less than $10 \mathrm{~s}$ of seismic data. Here, we will discuss how these data can be used to predict ground motions at more distant stations. Essentially, this is opposite of the study by Luo et al. (2010), which predicts near-in effects from distant stations.

Predicting the Effect of Directivity at Farther Stations

Based on the directivity analysis of $P$ waves, one can further estimate the site response. Here, we use broadband velocity tangential component for this test because $S H$ waves are generally regarded as the more destructive phases at stations with larger epicentral distances, although other components work equally well. We select four stations at $\sim 50 \mathrm{~km}$ away from the source. Stations CHF and WLT are in the direction of rupture, whereas stations BBS and MSJ are away from it (Fig. 9). Predicted waveforms are simulated by convolving the $M_{\mathrm{w}} 3.2$ event with an STF calculated from equation (2), based on the estimated rupture speed and direction from the $P$-wave analysis, as well as an assumed $S$-wave velocity $\left(V_{S}\right)$ of $3.18 \mathrm{~km} / \mathrm{s}$ at this depth, according to the 1D velocity model used in this study (see (E) Table S1). Our simulation produces excellent fits between predicted waveforms and the $M_{\mathrm{w}} 4.4$ data at all four stations (Fig. 9). For comparison, we also assume a rupture in the reverse direction (to the southeast) and simulate the corresponding waveforms (dashed line). A much worse fit results. The effect of directivity 

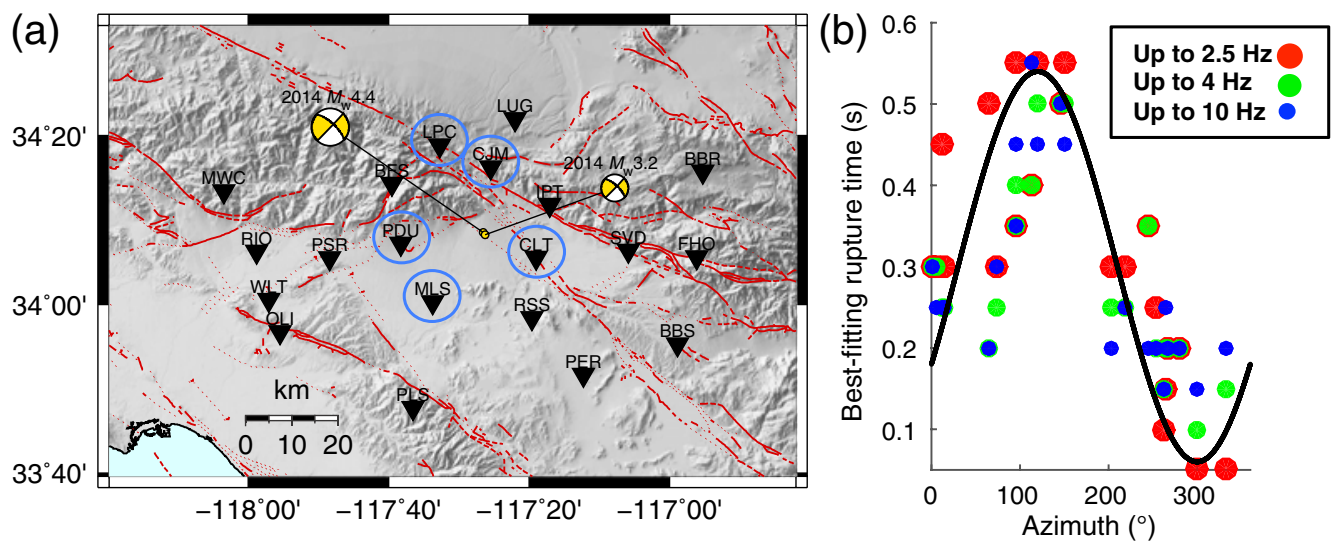

Figure 8. Sensitivity test of waveform at different frequency bands. (a) A map view showing all the stations included in this analysis. The five stations circled are selected for rapid directivity estimation using the first $3 \mathrm{~s}$ of $P$ waves, and the result is similar to when we include all the stations. (b) We obtain similar analysis results when using waveforms filtered to different frequency bands (up to $2.5,4$, and $10 \mathrm{~Hz}$ ). The color version of this figure is available only in the electronic edition.

is mostly revealed in the waveform amplitude rather than the pulse shape, but our simulations indicate that it is possible to quickly predict responses at larger distances provided that there are nearby smaller events available as EGFs for path corrections. The prediction of $S$ waves based on a calibrated STF is also validated by a grid search on a range of trapezoidal STFs (see (E) Fig. S7). The best-fitting EGF synthetics are very similar to those generated from the calibrated STF. Moreover, we are able to apply the same method and predict Rayleigh-wave motions (see (E) Fig. S8). When we choose a smaller event for EGF modeling, differences in focal mechanisms are allowed, as demonstrated by Tan and Helmberger (2007). Focal depth, however, remains an essential factor in levels of shaking.

\section{Implications for EEW and ShakeMap}

The extent of ground motion depends on both the direction of fault rupture and local geological materials. With the complicated tectonics in southern California, path effect plays a particularly important role in ground-motion prediction. Shallow events often generate secondary surface waves that follow the soft 3D tracks near the surface, as demonstrated in a study by Savage and Helmberger (2004) on the wave propagation through the Salton trough. Such motions are difficult to model because they are often highly pathdependent, as pointed out by C. Tape (personal comm., 2015) who performed extensive inversions of crustal surface waves. As a result, the EGF approach proposed here has significant advantages, because numerous small earthquakes are available in the region containing specific wavepath information. Work can begin on building an EGF library consisting of earthquakes in southern California. As an earthquake occurs, the library allows immediate identification and processing of a smaller event with similar location and depth, at the same time generating site-response predictions at greater distances when rupture properties of the main event become available and before seismic energy propagates into the area. Our methodology is particularly useful in predicting ShakeMaps and "Did You Feel It?" information due to aftershocks, which make a significant impact on populated regions as well as building responses. For example, the deep event received five times more reports than the shallow event (U.S. Geological Survey Community Internet Intensity Map) as expected from Figure 3.

In July 2015, an $M_{\mathrm{w}} 4.1$ earthquake occurred at a similar location in Fontana, at a depth of $5 \mathrm{~km}$. Together with the shallow event in 2014, they have both triggered building responses in a 9-story high-rise in Pasadena and a 15-story highrise in downtown Los Angeles, which are over $70 \mathrm{~km}$ from the epicenters (M. Kohler, personal comm., 2016). Currently, the EEW algorithm estimates the expected ground-motion intensity based on constrained earthquake location and seismic moment with $3 \mathrm{~s}$ of $P$ waves at nearby stations (Kanamori, 2005; $\mathrm{Wu}$ and Kanamori, 2005, 2008). Although these are of obvious value, accurate estimation of focal mechanism, depth, and rupture direction, besides being valuable information for early warning and the formulation of shake maps, will also be crucial for the engineering community to improve building response predictions.

\section{Impact of Large Earthquakes}

Exploring the scalability of this methodology is a subject of our ongoing research, taking advantage of station densifications. To understand the behavior and predictability of larger earthquakes, which occur much less frequently, requires realistic simulation of Green's functions. Deterministic and empirical methodologies are both used to generate events of greater size. As a test case, we take the latter approach and use available earthquakes as EGFs to simulate still bigger events. The big event is assumed to be a finite-fault earthquake, represented by the summation of a number of smaller events (Song et al., 1995, a study on the $M_{\mathrm{w}} 6.7$ Northridge earthquake in 1994). Here, the $M_{\mathrm{w}} 4.4$ shallow event near Fontana 


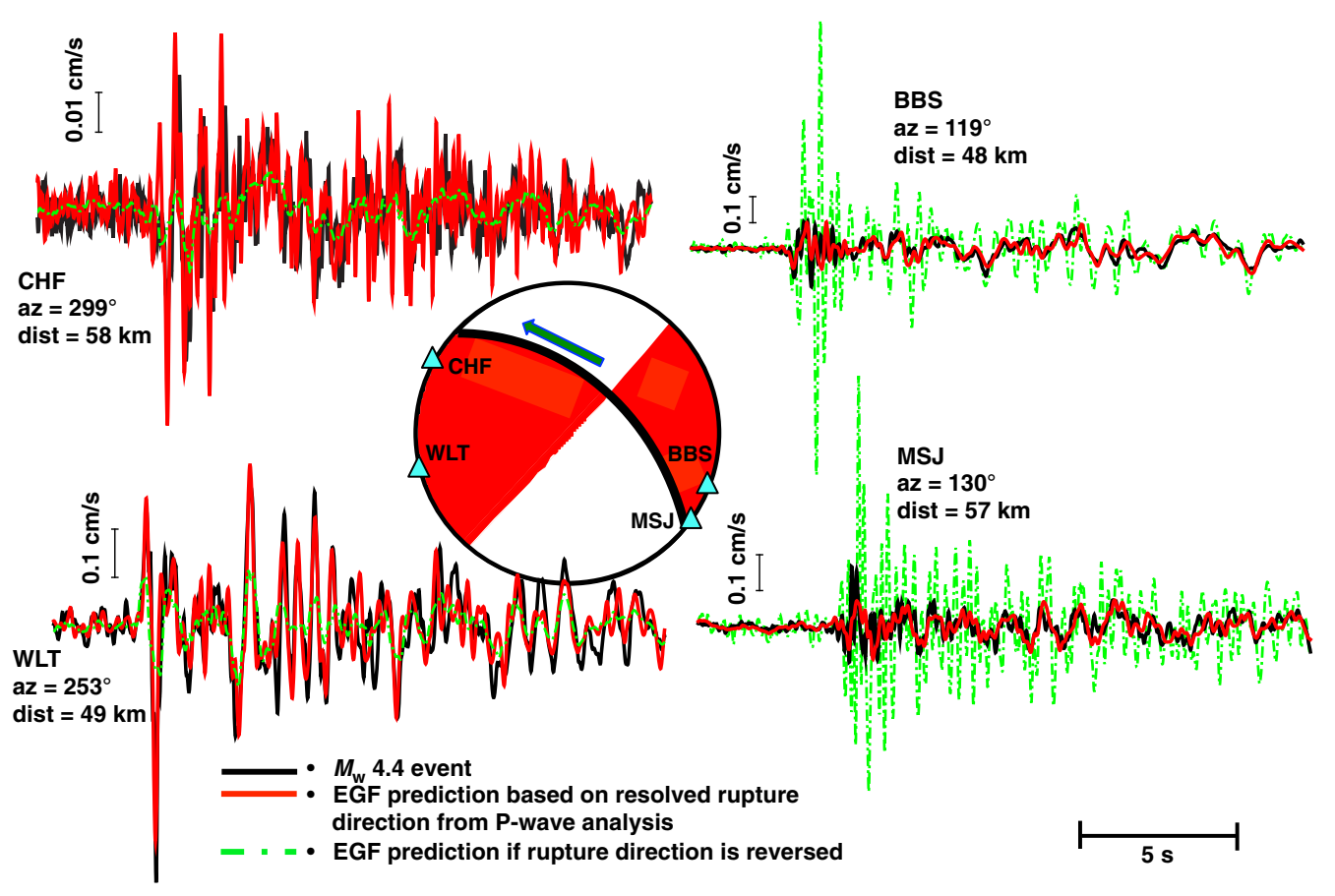

Figure 9. We can predict the amplitude of $S$-wave arrivals based on the $P$-wave directivity analysis. With estimated rupture length and velocity, one can compute the STF of $S$ waves and generate the prediction of site response for $S H$ waves (tangential component). Four stations are selected in this test, which are at different ends of the rupture plane. Rupture direction is indicated by the arrow. Waveform predictions have excellent fit with the $M_{\mathrm{w}} 4.4$ data. Dashed lines with significant differences in predictions occur if the rupture directions are reversed. The color version of this figure is available only in the electronic edition.

is summed 32 times to represent an $M_{\mathrm{w}} 5.4$ earthquake, with a rupture length of $2.8 \mathrm{~km}$ and rupture velocity of $2.9 \mathrm{~km} / \mathrm{s}$. Each point source is shifted by a small amount of time and adjusted for depth based on generalized ray theory, and in each test case they are aligned differently to model various rupture directions (Fig. 10a; Helmberger, 1983, Song and Helmberger, 1996). Notable differences in waveform amplitude and pulse shape can be seen at stations away from, and in the direction of, rupture. For full broadband records, waveform amplitude differs by a factor of 2 , depending on the azimuth of the stations from the earthquake source (Fig. 10b). Treating the line-source synthetic waveforms as real data, we then proceed with the directivity test as described in the previous section to resolve for corresponding STFs using the first $3 \mathrm{~s}$ of $P$ waves. Here, we use one of the $M_{\mathrm{w}} 5.4$ event simulations with rupture directing to the northwest. The resultant STFs are in excellent agreement with the assigned rupture direction (Fig. 10c). Waveform at station RSS, which is away from the rupture, fits best with a short and long STF, whereas station BFS, which is in the rupture direction, fits best with a tall and narrow STF. This is a good validation of our method and implies that the EGF library can be extended to earthquakes with $M_{\text {w }}$ larger than those in the existing catalog, further enhancing ground-motion estimations in real time when a big earthquake hits.

The methodology proposed in our study is useful in determining source characteristics of small-to-moderate events. Challenges will arise, nonetheless, as the earthquake grows larger in size and complexity, that is, at larger $M_{\mathrm{w}}$ the $P n l$ wavetrain spans a longer time window and the later phases will overlap with the first arrival of the direct $S$ wave. This adds complexity to the methodology, because it is difficult to separate the effects of multiple phases that arrive at the same time. At this point, one has to utilize a ring of stations that are slightly farther from the epicenter. This inevitably increases the time required to determine source characteristics, but the additional source information will still be beneficial for assessing what is happening as well as early responses. Although not discussed here, we are generating valuable information about the broadband rupture properties of earthquakes for use in numerical simulations at higher frequencies.

\section{Conclusion}

To summarize, we propose a systematic procedure that allows rapid assessment of the source characteristics and rupture properties of small-to-moderate earthquakes. A test case using earthquakes near Fontana, California, is successful in recovering moment magnitude, focal mechanism, and focal depth of the earthquake within $10 \mathrm{~s}$ after the first $P$-wave arrival. Rupture directivity can also be estimated from the first $3 \mathrm{~s}$ of $P$ waves using forward modeling of EGFs. Once rupture properties are constrained, the ground-motion response for the stronger $S$ waves that arrive later can be accurately predicted using EGFs in areas at farther distances. This set of methodology 
(a)
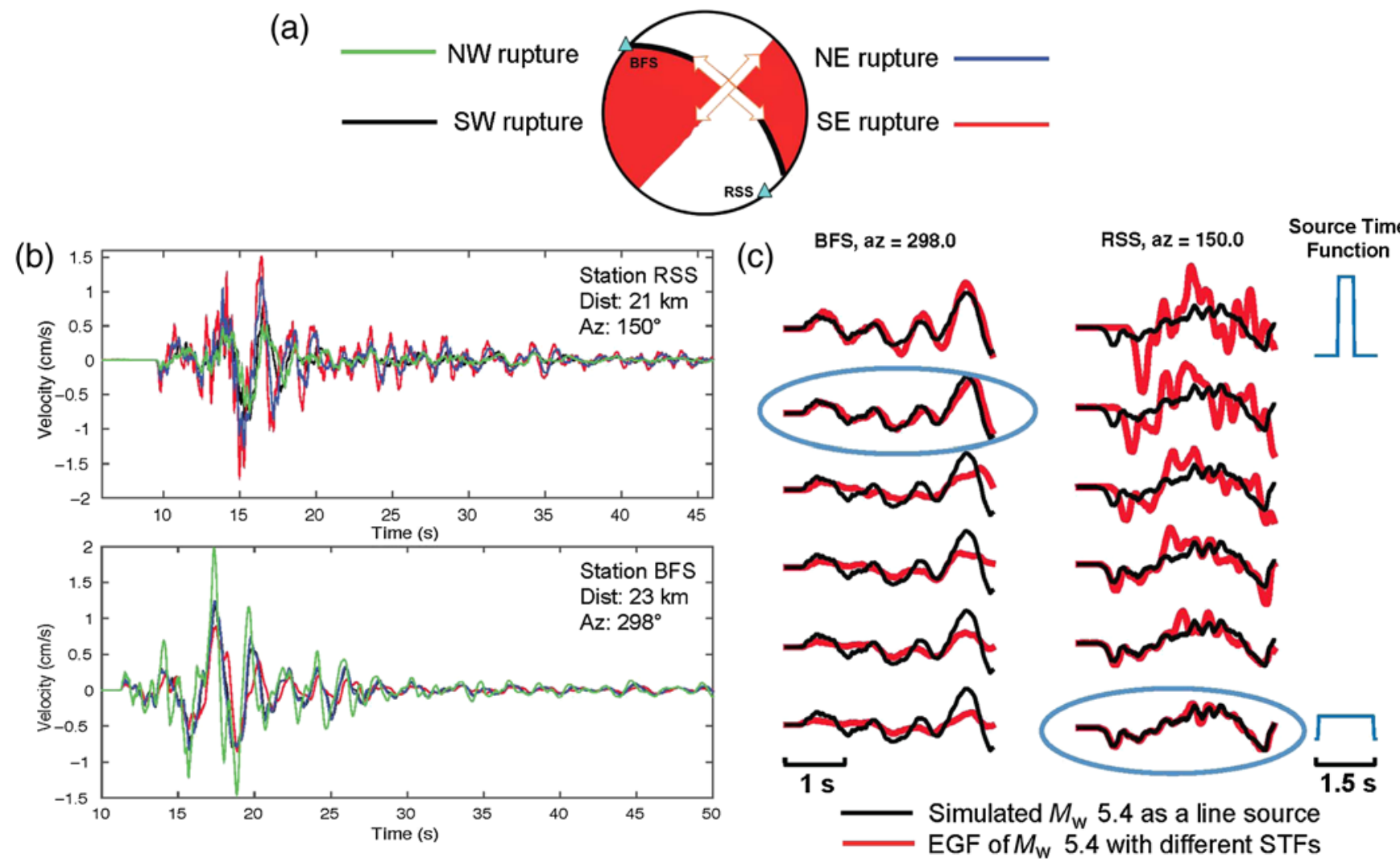

Figure 10. Simulating Green's functions of larger earthquakes using the EGF approach. (a) A finite-fault earthquake with $M_{\mathrm{w}} 5.4$ is represented by a summation of $32 M_{\mathrm{w}} 4.4$ point sources. Ruptures are simulated in four directions as indicated by the arrows. (b) Broadband EGFs of the $M_{\mathrm{w}} 5.4$ event at stations RSS (to the southeast) and BFS (to the northwest). (c) Result of directivity test with the $M_{\mathrm{w}} 5.4$ synthetic waveforms (b) treated as real data. The best-fitting pairs are circled. Resultant STFs are in agreement with the simulated rupture direction (northwest). The color version of this figure is available only in the electronic edition.

can potentially improve the effectiveness of the EEW system, contributing to the mitigation of seismic hazard.

\section{Data and Resources}

Broadband waveforms were obtained from the Southern California Seismic Network (SCSN). Some plots were made using the Generic Mapping Tools v.4.5.9 (Wessel and Smith, 1998).

\section{Acknowledgments}

This study is supported by U.S. Geological Survey (USGS) Grant G15AP00029 and Award DVH.00035-1-USGS.BROADBAND "Broadband Modeling of Large Earthquake Effects." We would also like to thank Robert W. Graves for his insightful comments.

\section{References}

Geng, J., Y. Bock, D. Melgar, B. W. Crowell, and J. S. Haase (2013). A new seismogeodetic approach applied to GPS and accelerometer observations of the 2012 Brawley seismic swarm: Implications for earthquake early warning, Geochem. Geophys. Geosyst. 14, no. 7, 2124-2142.

Hauksson, E., K. Felzer, D. Given, M. Giveon, S. Hough, K. Hutton, H. Kanamori, V. Sevilgen, and A. Yong (2008). Preliminary report on the 29 July $2008 M_{\mathrm{w}} 5.4$ Chino Hills, eastern Los Angeles basin, California, earthquake sequence, Seismol. Res. Lett. 79, no. 6, 855-866.
Helmberger, D. V. (1983). Theory and application of synthetic seismograms, in Earthquakes: Observation, Theory and Interpretation, H. Kanamori (Editor), Soc. Italiana di Fisica, Bologna, Italy, 173-222.

Helmberger, D. V., D. Dreger, R. Stead, and H. Kanamori (1993). Impact of broadband seismology on the understanding of strong motion, Bull. Seismol. Soc. Am. 83, no. 3, 830-850.

Jones, L. M., R. Bernknopf, D. Cox, J. Goltz, K. Hudnut, D. Mileti, S. Perry, D. Ponti, K. Porter, M. Reichle, and H. Seligson (2008). The shakeout scenario, U.S. Geol. Surv. Open-File Rept. 1150, 308 pp.

Kanamori, H. (2005). Real-time seismology and earthquake damage mitigation, Annu. Rev. Earth Planet. Sci. 33, 195-214.

Lui, S. K. Y., D. V. Helmberger, S. Wei, Y. Huang, and R. W. Graves (2015). Interrogation of the megathrust zone in the Tohoku-Oki seismic region by waveform complexity: Intraslab earthquake rupture and reactivation of subducted normal faults, Pure Appl. Geophys. 172, no. 12, 3425-3437.

Luo, Y., Y. Tan, S. Wei, D. Helmberger, Z. Zhan, S. Ni, E. Hauksson, and Y. Chen (2010). Source mechanism and rupture directivity of the 18 May $2009 M_{\mathrm{w}} 4.6$ Inglewood, California, earthquake, Bull. Seismol. Soc. Am. 100, no. 6, 3269-3277.

Savage, B., and D. V. Helmberger (2004). Complex Rayleigh waves resulting from deep sedimentary basins, Earth Planet. Sci. Lett. 218, no. 1, 229-239.

Song, X. J., and D. V. Helmberger (1996). Source estimation of finite faults from broadband regional networks, Bull. Seismol. Soc. Am. 86, no. 3, 797-804.

Song, X. J., L. E. Jones, and D. V. Helmberger (1995). Source characteristics of the 17 January 1994 Northridge, California, earthquake from regional broadband modeling, Bull. Seismol. Soc. Am. 85, no. 6, 1591-1603. 
Tan, Y., and D. V. Helmberger (2007). A new method for determining small earthquake source parameters using short-period $P$ waves, Bull. Seismol. Soc. Am. 97, no. 4, 1176-1195.

Tan, Y., and D. V. Helmberger (2010). Rupture directivity of the 2003 Big Bear sequence, Bull. Seismol. Soc. Am. 100, no. 3, 1089-1106.

Wei, S., J.-P. Avouac, K. W. Hudnut, A. Donnellan, J. W. Parker, R. W. Graves, D. Helmberger, E. Fielding, F. Cappa, and M. Eneva (2015). The 2012 Brawley swarm triggered by injection-induced aseismic slip, Earth Planet. Sci. Lett. 422, 115-125.

Wei, S., D. Helmberger, S. Owen, R. W. Graves, K. W. Hudnut, and E. J. Fielding (2013). Complementary slip distributions of the largest earthquakes in the 2012 Brawley swarm, Imperial Valley, California, Geophys. Res. Lett. 40, no. 5, 847-852.

Wessel, P., and W. H. Smith (1998). New, improved version of Generic Mapping Tools released, Eos Trans. AGU 79, no. 47, 579-579.

Wu, Y. M., and H. Kanamori (2005). Rapid assessment of damaging potential of earthquakes in Taiwan from the beginning of $P$ waves, Bull. Seismol. Soc. Am. 95, 1181-1185.

Wu, Y. M., and H. Kanamori (2008). Development of an earthquake early warning system using real-time strong motion signals, Sensors 8, 1-9.

Zhao, L., and D. V. Helmberger (1994). Source estimation from broadband regional seismograms, Bull. Seismol. Soc. Am. 84, 91-104.

Zhu, L., and D. V. Helmberger (1996). Advancement in source estimation techniques using broadband regional seismograms, Bull. Seismol. Soc. Am. 86, 1634-1641.

Zhu, L., and L. A. Rivera (2002). A note on the dynamic and static displacements from a point source in multilayered media, Geophys. J. Int. 148, no. $3,619-627$.

\section{Appendix}

\section{Additional Notes on Simulating Rupture as a Line of Point Sources}

In a layered half-space, the characteristic travel time of a generalized ray is given by

$$
t_{0}=p_{0} r+\sum_{i} \eta_{i} d_{i},
$$

in which $r$ is the source-receiver distance, $\eta_{i}$ is the vertical slowness of the ray in each layer, and $d_{i}$ is the vertical distance of the ray segment in each layer. Assuming the paths to the receiver to be highly similar for two very close seismic sources, one only has to account for the small difference in time shift $\left(d t_{0}\right)$, which can be approximated with Taylor series expansion for $t_{0}$ around the position of the point source $(r, h)$ :

$$
\partial t_{0}=\frac{\partial t_{0}}{\partial r} d r+\frac{\partial t_{0}}{\partial h} d h
$$

$\partial t_{0} / \partial r$ is essentially $p_{0}$ and is considered a constant in our analysis. $\left(\partial t_{0} / \partial h\right)=-\varepsilon \eta_{s}$, in which $\varepsilon=1$ and -1 for the downgoing and upgoing wave, respectively. $\eta_{s}$ is the vertical slowness of the ray $p_{0}$ in the source region. $p_{0}$ and $\eta_{s}$ in this study are numerical estimation from synthetics generated at different depths based on the velocity model used in cutand-paste inversion. Once the moment ratio $\left(r_{\text {mom }}\right)$ between the target event and the empirical Green's function (EGF) event is determined, we can discretize the rupture region into a line of $r_{\text {mom }}$ elements, each represented as an EGF-event point source. The total response of the target event at the receiver $(R(t))$ will be represented by a summation of the $r_{\text {mom }}$ rays, each properly lagged in time according to the relative position from the reference point source

$$
R(t)=\sum_{i=1}^{r_{\text {mom }}} g_{i}\left(t-d t_{0 i}\right)
$$

Hence, different rupture scenarios will show up differently due to a different amount of change in time shift.

Seismological Laboratory

Division of Geological and Planetary Sciences

California Institute of Technology

1200 East California Boulevard, MS 251-21

Pasadena, California 91125

klui@caltech.edu

(S.K.Y.L., D.H.)

CGG

10300 Town Park Drive

Houston, Texas 77072

(J.Y.)

Earth Observatory of Singapore (EOS)

Nanyang Technological University

50 Nanyang Avenue, Block N2-01a-15

Singapore 639798

(S.W.)
Manuscript received 9 April 2016; Published Online 18 October 2016 